\title{
Finance and economic growth nexus: evidence from Gansu province in China
}

\author{
Changchuan Zhang ${ }^{1 *}$ \\ ${ }^{1}$ International Business School Suzhou Xi'an Jiaotong-liverpool University Suzhou, Jiangsu 215123, China
}

\begin{abstract}
This study investigates the association between financial development and economic growth in the long run using the time series data from 1985 to 2018 in financially undeveloped Gansu province in China. Regarding methodology, this paper employs ADF unit root test, Johansen co-integration test, VECM and Granger causality test to analyze the long-term relationship. The outcomes signal that the variables of financial depth, financial efficiency and economic growth are co-integrated, and the level of total financial development is negatively correlated with economic growth while financial efficiency is positively associated with output growth. In addition, there is a two-way causation between each pair of variables.
\end{abstract}

\section{Introduction}

The relationship between financial development and economic growth has been discussed for a long time in economic research. Many economists argue that as a pivotal factor finance can promote economic development by increasing financial efficiency and adjusting financial structure, while others state that it is economic growth that accelerates financial development. However, in China the specific relationship is a more complex case. Because China is still in the process of improving the financial structure and although it has become the second largest economy in the world. There is still a gap between financial structures of China and western developed countries.

Compared with the market-type financing system in which the market plays a decisive role in the allocation of financial resources, China's financial system has typical characteristics of financial restraint, and the government plays a leading role in the allocation of financial resources. Particularly, China's financial system is characterized by a bank-oriented rather than market-oriented structure. Moreover, the discrepancies of financial development in different regions of China are distinct due to the difference in the spatial distribution of financial resource supply and demand. It is shown that there is distinct difference of agglomeration effects in regional financial development of China: the financial development in eastern area outperforms it in other regions, whereas middle and western areas are generally at the same level [1]. Similarly, Xiong and Tan using factor analysis method examine and rank the financial development level of 30 provinces in China, and conclude that there are clear differences in regional financial development — the financial development of developed coastal provinces is relatively high, and in central and western provinces is relatively low because of immature financial ecological environment and dysfunctional local financial system resulting in continuous stagnation [2].

Based on the various levels of financial development in different regions, the nexus between finance and economic growth can also be conjectured as an uncertain problem. Liu and Zhang detect the effect of financial structure on economic growth based on a panel data of three regions in China from 1996 to 2013, and conclude that the effect changes according to different regions and presents an U-shape [3]. Therefore, it is vital to note that it may be more enlightening if we examine the relationship between finance and economic growth according to a specific region in China, especially the less financially developed areas in which suggestions are highly needed to promote the local economy. However, most of the relevant studies are focusing on the overall direction related to national level or on the well-developed areas. Thus, we examine the potential relation based on evidence from less financially developed Gansu province, and may bring some new and indicative thoughts to the government and economics.

\section{Literature Review}

The earlier entry point of the causality between financial development and economic growth can be found through the discussion of the nature of financial services demand-following and supply-leading [4]. The demandfollowing approach indicates that the development of financial institutions are boosted by the expanding economy, which creates the increasing demand of finance to support the emerging and growing businesses; the supply-leading finance means that the growth of finance is the reason of economic growth for that the financial development is prior to the its intense demand, which will fund firms and then raise total output [4]. It therefore

*Corresponding author: Changchuan.Zhang18@student.xjtlu.edu.cn 
provides theoretical foundation to further analyze the causality in countries at different levels of development. Then Jung analyzing the data from 56 countries found that the supply-leading pattern takes a dominant position in less-developed countries, consistent with the argument of Patrick [5]. Furthermore, in temporal causality Jung shows that supply-lending and demand-following patterns will alternate during the process of development [5].

In addition, King and Levine took a different approach in measuring the association between financial development and economic growth. The estimation of financial development is segmented into four indicators financial depth, weights between deposit banks and central banks, credit distributed to private companies to total credit and to GDP [6]. They point out the short-term positive correlation between financial development and economic growth, and the contemporaneous changes will influence the long-run growth and make the relationship more complex [6]. Specifically, several economists argue that the operation of less efficient financial system can restrain the economic growth. McKinnon and Shaw presented the effect of financial regression, which can explain the economic gap between undeveloped and developed countries [7,8]. McKinnon observed that financial institutions are separated from small businesses and individuals in undeveloped firms, and argued that financial constraint should be relaxed to adjust to supplydemand mechanism [7].

Nevertheless, Ram analyzing the data of 95 countries argued that there is significantly weak correlation between financial development and economic growth, and moreover, the correlation of the average individual country differs from the cross-country correction [9]. Augustine and Pius using OLS analyze the long-run influence of development in stock market on the economic growth, and state that the market size and turnover ratios can bolster economic growth, whereas market liquidity coefficient is negatively correlated with economic growth [10].

Recently, more studies attempt to figure out the specific and detailed channel of financial development that affect the economic growth. Abdmoulah and Jelili apply the threshold effects to examine the possibility that financial improvement can influence the total output nonlinearly, and using data from 144 countries find that the universality of banking branches is one of the significant sources of economic growth [11]. Cojocaru et al. target the former CIS and CEE communist countries that transforming from undeveloped financial institutions from 1990 to 2008, and conclude that private credit is positively associated with economic growth but financial efficiency is more statistically significant than the private credit when weighing the effects to growth [12]. Additionally, Jerzmanowski chooses the timing of bank deregulation as an exogenous variable of financial development. It notices that deregulation can promote the economic growth irrespective of development levels of states and this effect is through both the increasing productivity and accumulation of physical capital [13]. Moreover, Ehigiamusoe and Lean report that the weak relationship between finance and economic growth in West Africa may be due to the low level of income and financial development and high inflation [14]. Rapp and Udoieva examine the function of financial structure in economic growth and conclude that financial systems equipped with large market size can better expedite economic growth [15]. However, Bucci and Marsiglio show that in certain situations the connection between finance and economic growth tend to deviate from a simple monotonicity [16].

There are scare literatures attempting to illustrate finance-growth nexus of undeveloped areas in China, especially the role of well-functioning banks. Multiple studies have emphasized that banks play a more important role in economic growth as the increase of services provided by financial markets. Banks makes a significant contribution to mitigate risks in financial market and allocate capital efficiently [17]. Furthermore, especially in developing countries where stock market has a limited impact on the long-term growth, banks can instead better facilitate economic growth through resource allocation [18]. Hence, considering the immature financial development in Gansu province this paper will discuss the result of economic growth motivated by finance focusing mainly on the banking system instead of stock market.

\section{Financial and Economic Development in Gansu}

Gansu is located in the northwest of China accounting for $4.72 \%$ of China's total area. Gansu's geographical location makes it a strategic base connecting the central regions and supporting the northwest. From the whole economic development strategy, Gansu is in the pivotal position of whether China can achieve social stability and common prosperity. However, there is an obvious gap between Gansu and the national average, especially the eastern coastal areas, in terms of economic aggregate and development level. Moreover, the financial development encounters hard challenge to optimize the resources allocation a hence to animate the potential economic growth. The objective existence of supply-demand imbalance directly restricts the development level of Gansu, which needs to be further solved and advanced.

\subsection{Financial Development}

The financial development in Gansu is below the average performance in China and even shows gradual weakening in a period. By the end of 2019, the balance of deposits in local and foreign currencies of financial institutions in Gansu province was 1976.85 billion yuan, an increase of $5.8 \%$ over that of the previous year. The balance of loans in domestic and foreign currencies of financial institutions was 2.06779 trillion yuan, up $6.7 \%$ [19]. The number of domestic listed companies was 33, which is the same as last year. Figure 1 describes the stock and flow of financial assets: the deposits and loans before 2000 maintained at a relatively low level with a steady growth; after 2000 total deposits started to significantly exceed the total loans. Figure 2 showing the financial efficiency defined as loans over deposits indicates that the overall efficiency is fluctuating around an evidently anemic level. The scale and direction of deposits and loans illustrate the capital 
utilization in Gansu reflecting the weakening financial development in Gansu that already in capital shortage to some extent. In addition, through the analysis of the proportion of various financial institutions in Gansu Province, the banking industry still positions at the mainstream and has formed obvious advantages after a long period of accumulation, while the proportion of security and insurance institutions is insufficient to satisfy the diversified demand trend in the economic market.

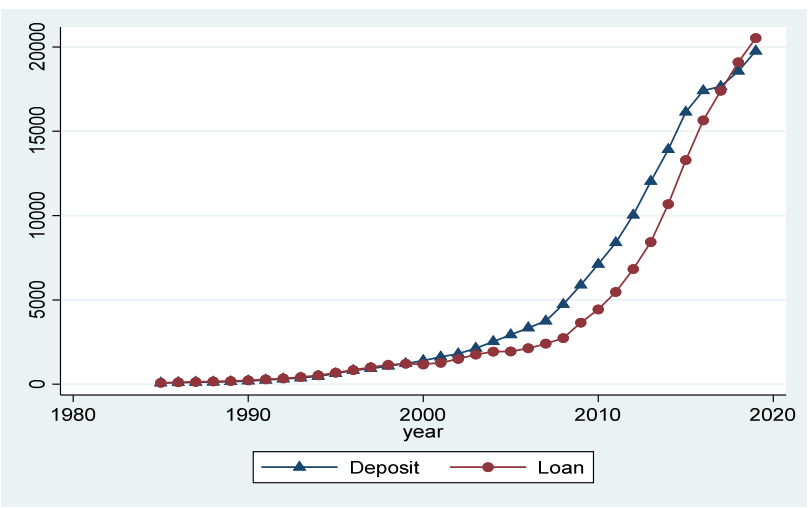

Figure 1. Deposits and credits from financial institutions.

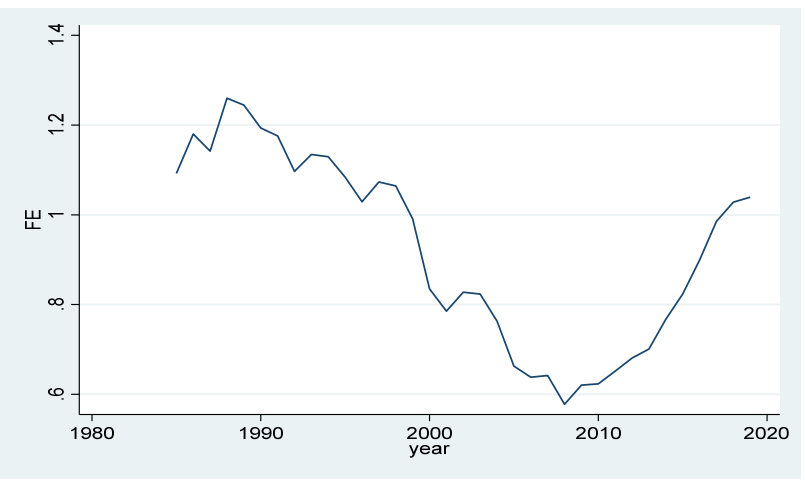

Figure 2. Financial efficiency

\subsection{Economic Development}

In recent years, under the environment of social and economic development in China, together with the establishment of a series of national policies, the economic aggregate of Gansu has shown a sustained growing trend (Figure 3). Based on this, the GDP and fixed asset investment of Gansu province also keep increasing but still lower than Xinjiang, Guangxi and other regions, and it is at the middle level in the development of the whole western region However, Gansu still maintains a stable growth and has the momentum and opportunity to abridge the gap given certain appropriate financial and industrial policies. In 2019, the GDP reached 871.83 billion yuan, an increase of $6.2 \%$ over the previous year, and the per capita GDP was 32,995 yuan, an increase of $5.7 \%$ over last year. Specifically, the value of the primary industry, the secondary industry and the tertiary industry increased by $5.8 \%, 4.7 \%$ and $7.2 \%$, respectively [19]. According to the above analysis, it can be seen that Gansu's economic and financial development is in a state of incomplete balance. The problems it faces are mainly in the aspects of single financing channels, weak savings capacity and unbalanced business development.

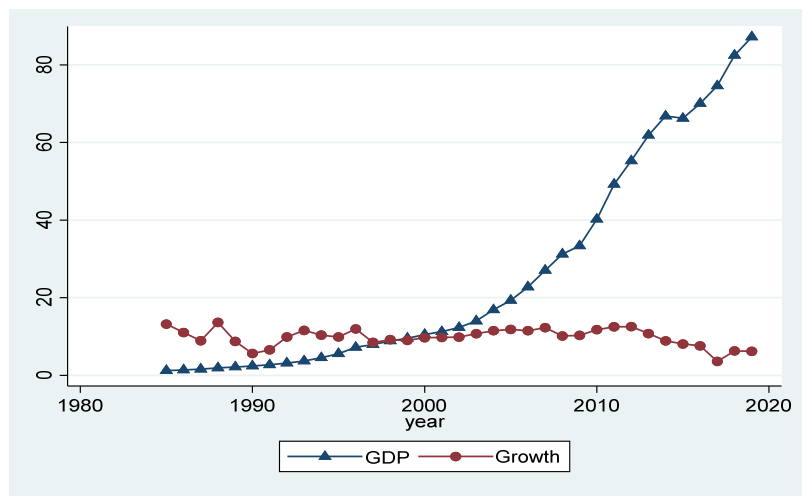

Figure 3. GDP and growth rate

\section{Data Sources and Description}

This paper has collected all the data from China Statistical Yearbooks Database and the website of The People's Bank Of China. The study is conducted based on the time-series data of Gansu province during 1985-2018. GDP per capita is used to better imply the economic growth eliminating the bias of population growth. According to the research of Goldsmith, Financial Interrelation Ratio (FIR) equal to a country's financial assets divided by GDP can be treated as the measurement of financial depth [20]. Moreover, we employ the ratio of bank loans and the amount of deposit as a substitution for financial efficiency (FE). In order to reduce the effect of heteroskedasticity, I take the natural $\log$ for all variables. Additionally, $\ln (\mathrm{FE}+1)$ is taken for $\mathrm{FE}$ to avoid the meaningless negative values. Figure 1 depicts the time series plots of the variables. GDP indicates an upward tendency while FIR and FE tend to have an opposite variation with GDP, implying the possible cointegrating relationship. Table 1 below shows the description of GDP, FIR and FE from 34 observations. The results indicate that the values of the three variables are not significantly isolated from the mean values and the volatility of the data is relatively small.

\section{Methodology}

To analyze the influence of financial development on economic growth, we borrow and adjust the model from King and Levine, and regress the growth per capita on the level of financial development and financial efficiency. We omit the impact of insurance industry and stock market to investigate the banking system in more detail considering the comparatively more significant impact of banks on economic growth [18]. The model is adopted and adjusted based on the research of Cojocaru et al [12]. Therefore, we build up the following equation:

$$
\mathrm{GDPt}=\alpha+\beta \mathrm{FIRt}+\gamma \mathrm{FEt}+\varepsilon \mathrm{t}
$$

where $\mathrm{t}$ refers to the time period, GDPt is the natural log of GDP per capita, FIRt represents the natural $\log$ of financial interrelation ratio, FEt is the natural log of financial efficiency plus one, $\alpha$ indicates the constant term 
and $\varepsilon$ is random disturbance. Total deposit and loan of financial institutions divided by GDP is a substitution for financial depth represented by FIR, and the ratio of loan and deposit is used as an index of financial efficiency. The natural $\log$ is taken for every index to mitigate the effect of heteroskedasticity. The concentration is to analyze the impact of financial depth $(\beta)$ and financial efficiency $(\gamma)$ on economic growth. This study firstly employs Augmented
Dickey-Fuller Test (ADF) to test unit root. Johansen cointegration test and Vector Error Correction Model (VECM) are utilized to investigate the long-term and short-term relationship among financial depth, financial efficiency and economic growth. Finally, Granger causality test is employed to detect the dynamic association among those variables and the predictability of direction.

Table1. The summary of the descriptive statistics

\begin{tabular}{llllll}
\hline Variable & Obs & Mean & Std. Dev. & Min & Max \\
\hline GDP & 34 & 8.51211 & 1.262045 & 6.410175 & 10.35252 \\
FIR & 34 & 0.9078699 & 0.3349897 & 0.2127289 & 1.551465 \\
FE & 34 & 0.6452646 & 0.1134592 & 0.4559757 & 0.8153626 \\
\hline
\end{tabular}

\section{Empirical Analysis}

\subsection{Unit Root Tests}

The method of unit root test for each variable is based on Augmented Dickey-Fuller Test [21]. Because LNGDP and LNFIR have the trend to grow over time, we therefore choose the ADF tests with trend. We conduct a series of
ADF tests based on the computation of the maximum order of lag recommended by Schwert [22]. Table 2 indicates that it cannot be rejected that the three variables have unit roots under 5\% level of probability, and that the series are non-stationary. However, the null hypothesis can be rejected for the first differences of the three variables and this implies the three variables are at integrated order one level. Therefore, this conforms to the prerequisite of co-integration test proceeded then.

Table2. Unit root test

\begin{tabular}{lrccc}
\hline & $\begin{array}{c}\text { Test } \\
\text { Statistic }\end{array}$ & $\mathbf{1 \%}$ Critical Value & $\mathbf{5 \%}$ Critical Value & $\mathbf{1 0 \%}$ Critical Value \\
\hline GDP & -2.914 & -4.334 & -3.58 & -3.228 \\
FIR & -2.305 & -4.334 & -3.58 & -3.228 \\
FE & 0.518 & -4.334 & -3.58 & -3.228 \\
$\boldsymbol{\Delta}$ GDP & -3.298 & -3.702 & -2.98 & -2.622 \\
$\boldsymbol{\Delta \text { FIR }}$ & -3.949 & -3.702 & -2.98 & -2.622 \\
$\boldsymbol{\Delta}$ FE & -3.994 & -3.702 & -2.98 & -2.622 \\
\hline
\end{tabular}

\subsection{Co-integration Test}

According to the results of stationary test, co-integration test can be further imposed to determine the number of cointegrating vectors. Firstly, it is essential to specify the order of lags for the vector error-correction model (VECM). The model with four lags is selected based on the Akaike's information criterion (AIC). Table 3 shows the result of Johansen test for cointegration. The trace statistic at $r=1$ of 13.2252 is less than the critical value of 18.17 , and therefore we can conclude there exists one cointegrating equation. The max statistic reaches the same result. Therefore, the co-integration test confirms that there is a cointegrating relationship among the three variables. Based on the conclusion of cointegration, we proceed to evaluate the model in long run using vector error-correction model.

\subsection{Vector Error Correction Model}

With the three times series proved to be first-difference stationary and cointegrating, VECM can be implemented to estimate the parameters of this cointegrating relationship between these variables. VECM can be modeled as a special form of the Vector Auto-Regression model with error correction terms to describe the short-run and long-run cointegrating relationship. Table 4 shows the result of long-run equation for VECM and the cointegrating equation can be implied by LNGDPt $=-5.5$ - 2.88LNFIRt +2.33 LNFEt. The coefficients and the overall cointegrating equation are both statistically significant at $1 \%$ significance level. The negative coefficient of LNFIR indicates that there is a negative association between economic growth and financial scale. The positive coefficient of LNFE implies that increasing financial efficiency can promote economic growth. The reason tends to show that the growth in Gansu province does not depend on the accumulation of total amount of fixed capital but relies on the improvement of efficiency of utilization for funds in the whole society. Table 5 indicates the result of the Lagrange-multiplier test for autocorrelation, implying the null hypothesis that there is no autocorrelation cannot be rejected for the tested orders at $5 \%$ level. Figure 2 displays the test result of eigenvalue stability condition in a VECM. Except the moduli specified in the VECM, all of the eigenvalues fall inside the unit circle, revealing that the cointegrating equation is stationary. 
Table3. Johansen tests for cointegration

\begin{tabular}{|c|c|c|c|c|c|}
\hline \multicolumn{4}{|c|}{ Trend: trend } & \multirow{2}{*}{\multicolumn{2}{|c|}{$\begin{array}{l}\text { Number of obs }=30 \\
\text { Lags }=4\end{array}$}} \\
\hline Sample: & 1989-2018 & & & & \\
\hline \multicolumn{6}{|c|}{ maximum } \\
\hline rank & parms & $\mathbf{L L}$ & eigenvalue & trace statistic & $5 \%$ critical value \\
\hline 0 & 33 & 196.23 & & 40.1437 & 34.55 \\
\hline 1 & 38 & 208.57 & 0.56068 & $15.4681^{*}$ & 18.17 \\
\hline 2 & 41 & 215.28 & 0.36105 & 2.0301 & 3.74 \\
\hline 3 & 42 & 216.30 & 0.06543 & & \\
\hline \multicolumn{6}{|c|}{ maximum } \\
\hline rank & parms & $\mathbf{L L}$ & eigenvalue & max statistic & $5 \%$ critical value \\
\hline 0 & 33 & 196.23 & & 23.7948 & 23.78 \\
\hline 1 & 38 & 208.57 & 0.56068 & 11.2481 & 16.87 \\
\hline 2 & 41 & 215.28 & 0.36105 & 1.9771 & 3.74 \\
\hline 3 & 42 & 216.30 & 0.06543 & & \\
\hline
\end{tabular}

Table4. Cointegrating equation

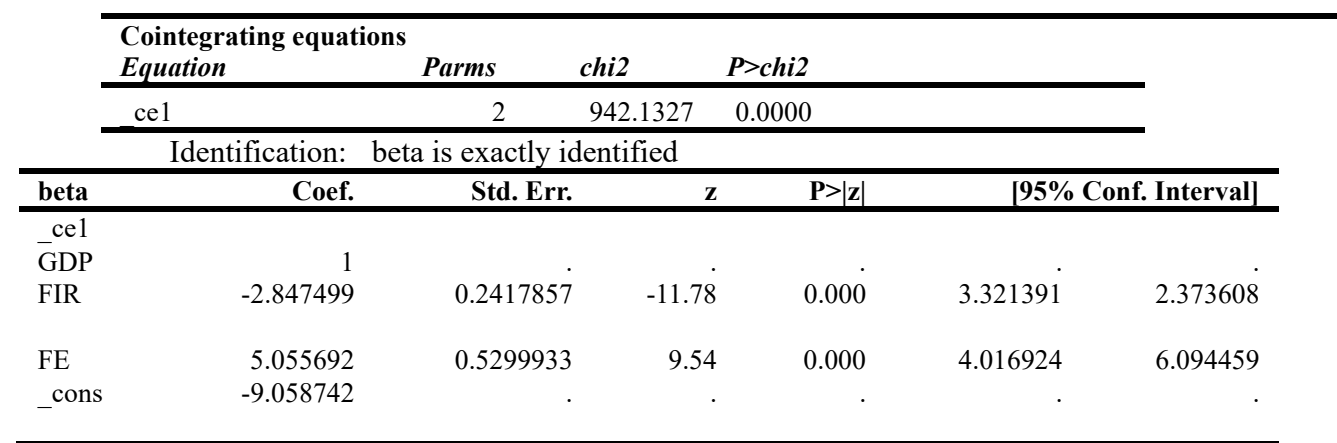

Johansen normalization restriction imposed

Table5. Lagrange-multiplier test for autocorrelation

\begin{tabular}{cccc}
\hline lag & chi2 & df & Prob > chi2 \\
\hline 1 & 6.8236 & 9 & 0.65547 \\
2 & 8.5973 & 9 & 0.47525 \\
3 & 3.7486 & 9 & 0.92717 \\
4 & 5.9317 & 9 & 0.74674 \\
\hline
\end{tabular}

\subsection{Granger Causality Test}

After generating the VECM, the Granger causality test based on temporal precedence can be conducted to analyze causal links between cointegrating variables under VECM. From Table 6, the zero p-values confirm that LNGDP, LNFIR and LNFE have a reciprocal Granger causal relationship. The results indicate significant Granger casual correction among financial depth, financial efficiency and growth, meaning that the improvement in financial development and efficiency can ameliorate economic growth. Additionally, the directional link from GDP to financial development also points out that the economic growth in Gansu province can also promote the local financial development and efficiency.

\section{Result and Discussion}

Based on the result of VECM, the coefficients of financial depth and financial efficiency are both significant at $1 \%$ level, indicating a strong goodness of fit. The negative and positive coefficients of FIR and FE illustrate that the amount of financial assets does not directly ameliorate economic growth in a healthy manner while financial efficiency plays a positive role in enhancing growth. The Granger causality test further reveals that financial development is indeed helpful in predicting economic growth. There are several aspects that may explain the abnormality. Firstly, the amount of credit may be excessively skewed towards state sectors, whereas private sectors have not obtained enough financial support, as a result of too much government intervention from allocation of financial assets. Secondly, this might be due to the low efficiency of financial institutions dominated by the state-owned banks. Therefore, the government should focus on how to distribute the financial resources 
effectively to facilitate the real economy especially the small and start-up enterprises and private economy.

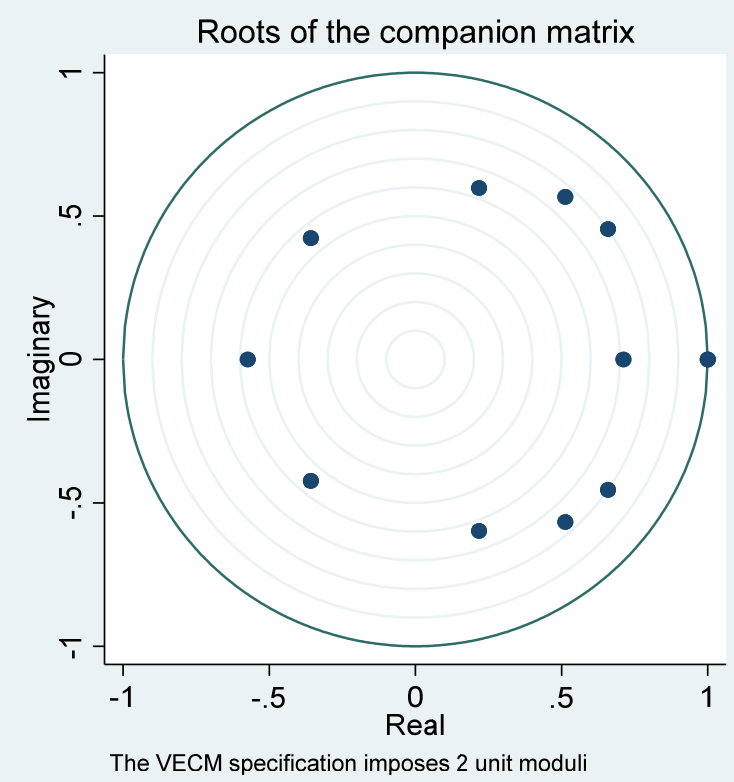

Figure 4. Test for stability of VECM

Table6. Granger causality results

\begin{tabular}{lllll}
\hline Equation & Excluded & chi2 & df & Prob $>$ chi2 \\
\hline GDP & FIR & 11.699 & 1 & 0.000 \\
GDP & FE & 35.666 & 1 & 0.000 \\
GDP & ALL & 35.807 & 2 & 0.000 \\
\hline FIR & GDP & 65.23 & 1 & 0.000 \\
FIR & FE & 31.281 & 1 & 0.000 \\
FIR & ALL & 71.525 & 2 & 0.000 \\
\hline FE & GDP & 15.752 & 1 & 0.000 \\
FE & FIR & 16.366 & 1 & 0.000 \\
FE & ALL & 17.436 & 2 & 0.000 \\
\hline
\end{tabular}

\section{Conclusion and Recommendation}

The purpose of this study is to detect the causality corrections between financial development and economic growth in underdeveloped areas in China. The time series of data of Gansu province from 1985 to 2019 is used to conduct the empirical analysis. The time series are found to be non-stationary under the unit root test based on ADF, whereas the first difference is tested to be stationary. Johansen test for co-integration then employed demonstrates that the three variables exist long-run cointegrating association. We build the Vector ErrorCorrection Model based on cointegrating association, indicating that financial depth does not significantly promote the economic growth in Gansu, consistent with the analysis of its unbalance between the demand of finance and economic growth, whereas there is a positive connection between economic growth and financial efficiency. The Granger causality test signals that GDP, FIR and FE are Granger causalities for each other. The results reveal the imbalance between financial development and economic growth, and tend to indicate that the expansion of the size of finance does not significantly promote the output growth while increase in financial efficiency is the main source of financial development contributing to economic growth.

According to the discussion of the empirical analysis of relationship between financial development and output growth, this paper proposes the following recommendations to help improve the unbalanced situation in less financially developed areas such as Gansu. Firstly, considering the monotonous constitution of financial department that is mainly directed by stateowned banks, it is foremost to encourage and attract new commercial banks, non-state-owned commercial banks and even foreign banks to establish branches in Gansu for 
the sake of supplement of financial support for small and medium businesses. The loans inclined to state-owned enterprises partially ignore and hinder the development of multiple private enterprises, constituting the primary reason of low efficiency for financial institutions. Therefore, it is vital to balance the and optimize the structure of loans. In this regard, Gansu province should start from the source of economic and financial development and concentrate on the areas with low savings-investment transformation to guide and foster the development of the capital market so as to conserve energy for economic growth. Particularly, the government should fully utilize the advantages of administrative functions, follow the development trend of information age and strengthen the supervision of the network information platform

\section{References}

1. Zheng, S., Huang, M. (2015) An Analysis of Factors Influencing Regional Financial Development based on Bayesian Spatial Econometric Model. Commercial Research, 1: 62-69.

2. Xiong, X., Tan, L. (2016) The Measurement and Comparative Analysis on Regional Financial Development Level in China---Based on the Provincial Panel Data from 2004 to 2013. Economy and Management, 30(5): 72-78.

3. Liu, G., Zhang, C. (2020) Does financial structure matter for economic growth in China. China Economic Review, 61.

4. Patrick, H.T. (1966) Financial Development and Economic Growth in Underdeveloped Countries. Economic Development and Cultural Change, 14: 174-189.

5. Jung, W.S. (1986) Financial Development and Economic Growth: International Evidence. Economic Development \& Cultural Change, 34(2): 333.

6. King, R.G., Levine, R. (1993) Finance and Growth: Schumpeter Might be Right. The Quarterly Journal of Economics, 108(3): 717-737.

7. McKinnon, R. (1973) Money and Capital in Economics. Brookings Institution, Washington DC.

8. Shaw, E. (1973) Financial Deepening in Economic Development. Oxford University Press, New York.

9. Ram, R. (1999) Financial Development and Economic Growth: Additional Evidence. Journal of Development Studies, 35(4): 164.

10. Augustine, U., Pius, S.O. (2010) Stock market development and economic growth: evidence from Nigeria. European Journal of Economics, Finance and Administrative Sciences, 25: 44-53.

11. Abdmoulah, W., Jelili, R.B. (2013) Access to Finance Thresholds and the Finance-Growth Nexus. Economic Papers, 32(4): 522-534.

12. Cojocaru, L., Falaris, E.M., Hoffman, S.D., Miller, J.B. (2016) Financial System Development and Economic Growth in Transition Economies: New
Empirical Evidence from the CEE and CIS Countries. Emerging Markets Finance \& Trade, 52(1): 223-236.

13. Jerzmanowski, M. (2017) Finance and sources of growth: evidence from the U.S. states. Journal of Economic Growth, 22(1): 97-122.

14. Ehigiamusoe, K.U., Lean, H.H. (2018) FinanceGrowth Nexus: New Insights from the West African Region. Emerging Markets Finance \& Trade, 54(11): 2596-2613.

15. Rapp, M.S., Udoieva, I.A. (2018) What matters in the finance-growth nexus of advanced economies? Evidence from OECD countries. Applied Economics, 50(6): 676-690.

16. Bucci, A., Marsiglio, S. (2019) Financial development and economic growth: long-run equilibrium and transitional dynamics. Scottish Journal of Political Economy, 66(3): 331-359.

17. Coval, J.D., Thakor A.V. (2005). Financial Intermediation as a Beliefs-Bridge between Optimists and Pessimists. Journal of Financial Economics 75(3): 535-569

18. Singh, A, Weisse, B.A. (1998) Emerging stock markets, portfolio capital flows and long-term economic growth: micro and macroeconomic perspectives. World Development, 26(4): 607-622

19. Gansu Development Yearbook Editorial Board. (2019) Gansu Development Yearbook.

20. Goldsmith, R. (1969) Financial Structure and Development. Yale University Press, New Haven.

21. Dickey, D.A., Fuller W.A. (1979) Distribution of the estimators for autoregressive time series with a unit root. Journal of the American Statistical Association, 79(366): 355-367.

22. Schwert, G.W. (1989) Tests for unit roots: a monte carlo investigation. Journal of Business \& Economic Stats, 7(2): 147-159. 